\title{
Comparison of the Efficacy of Ultrasound-Guided Microwave Ablation of Parathyroid Adenoma with Surgical Procedures
}

\author{
Jiehao Huang*, Wei Xu", Can Liu\# \\ The First Hospital Affiliated to Yangtze University, Jingzhou First People's Hospital, Jingzhou, China \\ Email: 355610093@qq.com, "673059878@qq.com,"1cwhtj@qq.com
}

How to cite this paper: Huang, J.H., $\mathrm{Xu}$, W. and Liu, C. (2021) Comparison of the Efficacy of Ultrasound-Guided Microwave Ablation of Parathyroid Adenoma with Surgical Procedures. Yangtze Medicine, 5, 171-178.

https://doi.org/10.4236/ym.2021.53017

Received: January 17, 2021

Accepted: September 12, 2021

Published: September 15, 2021

Copyright $\odot 2021$ by author(s) and Scientific Research Publishing Inc. This work is licensed under the Creative Commons Attribution International License (CC BY 4.0).

http://creativecommons.org/licenses/by/4.0/

\begin{abstract}
Objective: To compare the clinical efficacy and safety of ultrasound-guided microwave ablation with surgery for the treatment of primary parathyroid adenoma. Methods: The clinical data of patients with primary parathyroid adenoma admitted to the First Hospital of Yangtze University from January 2010 to May 2020 were retrospectively analyzed, and they were divided into 43 cases in the microwave ablation group (MWA) and 39 cases in the surgical procedure group (SR) according to the different treatment methods. The surgical condition, postoperative complications, and changes in serum parathyroid hormone (PTH) and serum calcium and phosphorus levels were analyzed in both groups. Results: The hospital stay and operation time of patients in the microwave ablation group were shorter than those in the surgical group, and the intraoperative bleeding was significantly less than that in the surgical group $(\mathrm{P}<0.05)$; the serum parathyroid hormone $(\mathrm{PTH})$, blood calcium and blood phosphorus levels of patients in both groups were significantly lower than those before treatment $(\mathrm{P}<0.05)$ after surgery of 1,3 and 6 months respectively, and the differences between groups were not statistically significant $(P>0.05)$. There was no statistically significant difference in the incidence of postoperative complications between the two groups $(\mathrm{P}>0.05)$. Conclusion: Microwave ablation can achieve the same therapeutic effect as surgery. It is a safe and feasible clinical technique worthy of clinical promotion with its short hospitalization time, less bleeding and less trauma.
\end{abstract}

\section{Keywords}

Primary Parathyroid Adenoma, Microwave Ablation, Surgical Procedure, Parathyroid Hormone

\footnotetext{
${ }^{\star}$ First author.

${ }^{*}$ Corresponding author.
} 


\section{Introduction}

Parathyroid adenoma is one of the main causes of hyperparathyroidism, which accounts for $80 \%-85 \%$ of primary hyperparathyroidism [1]. Hyperparathyroidism is a disorder of endocrine function. By taking advantage of the systemic distribution of parathyroid hormone, numerous target targets, rapid and sensitive effects, hyperparathyroidism is characterized by "small local lesions and large systemic effects" [2]. Surgical resection is the traditional treatment for primary parathyroid adenomas, and microwave ablation is a minimally invasive non-surgical treatment for them. Microwave ablation can inactivate adenoma activity, reduce serum parathyroid hormone and calcium levels, and alleviate adenoma-related symptoms [3]. This study will investigate the efficacy of ultrasound-guided microwave ablation treatment of parathyroid adenoma and surgical treatment, and then conduct a comparative study. The efficacy of these two treatments will be studied by comparing the indexes before and after the surgery, such as preoperative and postoperative serum calcium, phosphorus and parathyroid hormone, length of hospital stay, duration of surgery, complications of laryngeal recurrent nerve injury and so on, so as to provide a better choice for the clinical treatment of parathyroid adenoma.

\section{Data and Methods}

\subsection{General Data}

The clinical data of primary parathyroid adenoma patients admitted to the First Hospital of Yangtze University from January 2010 to May 2020 were retrospectively analyzed, and they were divided into 43 cases in the microwave ablation group and 39 cases in the surgical group according to the different treatment methods. Patients who met the following criteria were enrolled: patients diagnosed with primary hyperparathyroidism according to the recommendations of the International Symposium on Primary Hyperparathyroidism (82 cases), those excluded from ectopic parathyroidism by CT and 99MTC-Sestamibi radionuclides, and those confirmed to be benign parathyroid adenoma by ultrasunionguided core needle biopsy (CNB). This retrospective study was approved by the ethics committee of the First Hospital of Yangtze University, and written informed consent was obtained from each patient before the surgery.

\subsection{Methods}

All patients got the inspections of ultrasonic, CT, 99mTc-Sestamibi nuclide imaging, $\mathrm{CNB}$ and laboratory, and clinical symptoms assessment. CNB was performed under ultrasound guidance using a 16-gauge semiautomatic biopsy needle. Laboratory tests included determination of serum parathyroid hormone (normal range $11-67 \mathrm{pg} / \mathrm{mL}$ ), blood phosphorus levels (reference range 0.80 $1.50 \mathrm{mmol} / \mathrm{L}$ ) and blood calcium (normal range $2.00-2.65 \mathrm{mmol} / \mathrm{L}$ ), as well as coagulation tests and platelet counts. 


\subsubsection{Microwave Ablation Group}

Before ablation, venous access was established, and the patient was placed in a flat position with the neck hyperextended and the head tilted to the side, and the puncture site was routinely disinfected, toweled, and the puncture site and the puncture path were locally anesthetized with $2 \%$ lidocaine. For parathyroid nodules with rich color Doppler flow signals, the "vascular tip ablation" technique was used before ablation. Microwave antennas are placed in the appropriate colored areas to ablate the main blood supply vessels until the apparent colored blood flow around the parathyroid nodule disappears. Under the guidance of ultrasound, normal saline was injected into the area between the parathyroid nodules and the important structures in the neck (carotid artery, trachea, esophagus, nerve and thyroid) to form a fluid separation area of $3-5 \mathrm{~mm}$. Afterwards, the microwave ablation needle was placed into the lesion, and the microwave ablation instrument was activated with $40 \mathrm{~W}$ power to ablate the lesion point by point and surface by surface until all of the lesion showed strong echogenicity. Ultrasound contrast agent (SonoVue) was injected intravenously to evaluate the ablation effect in real time, and then the tissue in the ablated area was removed with a biopsy needle and sent for examination. Throughout the ablation procedure, the operator intermittently asks the patient how they feel to assess their vocal status. At the end of the treatment, the puncture point of the neck of the patient was observed for compression for $30 \mathrm{~min}$.

\subsubsection{Surgical Group}

After general anesthesia with tracheal intubation, an incision was made along the top two finger widths of the sternum, then the deep fascia was incised to expose the thyroid envelope, and the thyroid gland and the pseudo-envelope were carefully separated. The parathyroid adenoma is located in the terminal branches of the upper and lower thyroid arteries. After separating it from the surrounding tissue, the vessels are cut and the adenoma is completely removed. Care should be taken to protect the patient's trachea and esophagus during the neck incision and to protect the laryngeal recurrent nerve. After completing the surgery, the surgical incision was closed layer by layer.

\subsection{Observation Index}

1) Hospital stay, operation time and intraoperative blood loss.

2) Analyze the changes of serum parathyroid hormone (PTH), serum calcium and phosphorus levels before and after surgery of 1, 3 and 6 months respectively in both groups.

3) Postoperative complications such as headache, hypocalcemia, and laryngeal return nerve injury.

\subsection{Equipment Used}

ARIETTA 70 color Doppler ultrasound diagnostic instrument with $8-13 \mathrm{MHz}$ high frequency probe; microwave ablation using KY-2000 microwave ablation 
instrument-frequency $2450 \mathrm{MHz}$ with ablation power $40 \mathrm{~W}$; the matching microwave antenna needle is Thy-ablation ${ }^{\mathrm{TM}} 3 \mathrm{~mm} \times 18 \mathrm{G} ; 16 \mathrm{G}$ semi-automatic biopsy needle; SonoVue ultrasound contrast agent.

\subsection{Statistical Analysis}

SPSS 21.0 software was used for data processing. The measurement data were expressed as $\bar{x} \pm \mathrm{s}$ (mean \pm standard deviation), and the $t$-test was used for the intergroup test; the count data were expressed as frequencies and percentages and tested by $c^{2}$-test; $\mathrm{P}<0.05$ indicated a difference which means the data was statistically significant.

\section{Results}

\subsection{Comparison of General Data between the Two Groups}

20 men and 23 women in the microwave ablation group, aged from 35 to 70 years old (58.4 \pm 12.1 years old on average), with a disease duration of $5-21$ months ( $16.9 \pm 4.5$ months on average); there were 19 men and 20 women in the surgical group, aged from 36 to 72 years old ( $57.7 \pm 11.8$ years old on average), and the course of disease ranged from 4 to 19 months (15.4 \pm 3.7 months on average). When comparing the general data of the two groups, the differences were not statistically significant $(\mathrm{P}>0.05)$, which means the data were comparable. See Table 1.

\subsection{Comparison of Surgical Situation between the Two Groups}

The hospital stay and operation time of patients in the microwave ablation group were shorter than those in the surgery group, and the intraoperative bleeding was significantly less than that in the surgery group $(\mathrm{P}<0.05)$. See Table 2.

\subsection{Comparison of the Changes of PTH, Blood Calcium and Blood Phosphorus Levels in the Two Groups before and after Surgery}

The serum parathyroid hormone (PTH), blood calcium and blood phosphorus levels of patients in the two groups were significantly lower than those before treatment $(\mathrm{P}<0.05)$ after surgery of 1,3 and 6 months respectively, and the differences between the groups were not statistically significant $(P>0.05)$. See Table 3 .

\subsection{Comparison of Complications between the Two Groups}

There was one case of headache, two cases of hoarseness and one case of hypocalcemia in the microwave ablation group, while there was no patient with headache but two cases of hoarseness and one case of hypocalcemia in the surgical surgery group. There was no statistically significant difference in the incidence of complications between the two groups. See Table 4 . 
Table 1. Comparison of general information of patients between the two groups.

\begin{tabular}{cccc}
\hline Group & $\begin{array}{c}\text { Sex ratio } \\
(\mathrm{M} / \mathrm{F}, \text { cases })\end{array}$ & $\begin{array}{c}\text { Age } \\
(\text { years, } \bar{x} \pm \mathrm{s})\end{array}$ & $\begin{array}{c}\text { Mean duration of disease } \\
\text { (month, } \bar{x} \pm \mathrm{s})\end{array}$ \\
\hline Microwave ablation group & $20 / 23$ & $58.4 \pm 12.1$ & $16.9 \pm 4.5$ \\
Surgical group & $19 / 20$ & $57.7 \pm 11.8$ & $15.4 \pm 3.7$ \\
$t$-value & & 0.26 & 1.64 \\
$P$-value & 0.79 & 0.11 \\
\hline
\end{tabular}

Table 2. Comparison of patients' surgical conditions between the two groups $(\bar{x} \pm \mathrm{s})$.

\begin{tabular}{cccc}
\hline Group & $\begin{array}{c}\text { Operating } \\
\text { time }(\mathrm{min})\end{array}$ & $\begin{array}{c}\text { Intraoperative bleeding } \\
\text { volume }(\mathrm{mL})\end{array}$ & $\begin{array}{c}\text { Hospitalization } \\
\text { time }(\mathrm{d})\end{array}$ \\
\hline Microwave ablation group & $28.22 \pm 6.31$ & $6.45 \pm 1.33$ & $3.04 \pm 0.13$ \\
Surgical group & $92.47 \pm 16.42$ & $50.39 \pm 8.99$ & $5.88 \pm 2.12$ \\
$t$-value & 24.56 & 31.71 & 8.68 \\
$P$-value & 0.00 & 0.00 & 0.00 \\
\hline
\end{tabular}

Table 3. Comparison of the values of PTH, blood calcium and blood phosphorus levels at each time point after treatment between the two groups $(\bar{x} \pm s)$.

\begin{tabular}{|c|c|c|c|c|c|}
\hline Indicator & Group & $\begin{array}{l}\text { Before } \\
\text { treatment }\end{array}$ & 1 month & 3 months & 6 months \\
\hline \multirow{2}{*}{$\begin{array}{c}\text { PTH } \\
(\mathrm{pg} / \mathrm{mL})\end{array}$} & $\begin{array}{c}\text { Microwave } \\
\text { ablation group }\end{array}$ & $591.1 \pm 100.6$ & $308.2 \pm 31.0^{\mathrm{a}}$ & $267.7 \pm 26.5^{\mathrm{a}}$ & $162.4 \pm 11.9^{a}$ \\
\hline & Surgical group & $606.9 \pm 98.3$ & $299.4 \pm 33.8^{\mathrm{a}}$ & $263.8 \pm 20.2^{\mathrm{a}}$ & $158.6 \pm 11.3^{\mathrm{a}}$ \\
\hline \multirow{2}{*}{$\begin{array}{c}\text { Blood } \\
\text { calcium } \\
(\mathrm{mmol} / \mathrm{L})\end{array}$} & $\begin{array}{c}\text { Microwave } \\
\text { ablation group }\end{array}$ & $2.81 \pm 0.45$ & $2.26 \pm 0.37^{\mathrm{a}}$ & $2.01 \pm 0.22^{\mathrm{a}}$ & $1.57 \pm 0.18^{\mathrm{a}}$ \\
\hline & Surgical group & $2.97 \pm 0.50$ & $2.13 \pm 0.33^{\mathrm{a}}$ & $2.26 \pm 0.24^{\mathrm{a}}$ & $1.53 \pm 0.15^{\mathrm{a}}$ \\
\hline \multirow{2}{*}{$\begin{array}{c}\text { Blood } \\
\text { phosphorus } \\
(\mathrm{mmol} / \mathrm{L})\end{array}$} & $\begin{array}{c}\text { Microwave } \\
\text { ablation group }\end{array}$ & $2.51 \pm 0.72$ & $1.85 \pm 0.55^{\mathrm{a}}$ & $1.52 \pm 0.44^{\mathrm{a}}$ & $1.36 \pm 0.25^{\mathrm{a}}$ \\
\hline & Surgical group & $2.44 \pm 0.65$ & $1.34 \pm 0.49^{\mathrm{a}}$ & $1.48 \pm 0.41^{\mathrm{a}}$ & $1.38 \pm 0.27^{\mathrm{a}}$ \\
\hline
\end{tabular}

Note: Comparison of each time point with pre-treatment, ${ }^{\mathrm{a}} \mathrm{P}>0.05$, no statistically significant difference between the two groups.

Table 4. Comparison of postoperative complications between the two groups (\% of cases).

\begin{tabular}{ccccc}
\hline Group & Headache & Hoarseness & Hypocalcemia & Total \\
\hline Microwave ablation group & $1(2.3 \%)$ & $2(4.7 \%)$ & $1(2.3 \%)$ & $4(9.3 \%)$ \\
Surgical group & $0(0)$ & $2(5.1 \%)$ & $1(2.6 \%)$ & $3(7.7 \%)$ \\
\hline
\end{tabular}

\section{Discussion}

Parathyroid adenomas can occur at any age, with a significantly higher incidence after the age of 40 years, and can be associated with clinical symptoms. The incidence is more frequent in women than in men, with a ratio of 3:1 to 4:1 [4]. 
CT is easy to locate the ectopic parathyroid gland, for example, the ectopic parathyroid gland in the anterior mediastinum or in the tracheoesophageal sulcus. However, CT is costly and radiologically intensive, and enhanced scans are important but dependent on the hematologic status of the parathyroid glands [5] [6]. Methoxyisobutylisocyanine (MIBI) imaging technique is highly sensitive for detecting solitary adenomas and is the preferred nuclide imaging test. The biggest drawback of MIBI is its low sensitivity for polyglandular hyperplastic parathyroid lesions (sensitivity of 45\%) and double adenomas (sensitivity of 30\%). The sonogram of a parathyroid adenoma is usually hypoechoic, unlike the hyperechogenicity of a follicular thyroid nodule. The most common parathyroid adenoma is oval in shape, but can appear elongated, bilobed or multilobed [7]. The advantages of ultrasonography are: 1) accuracy and reliability; 2) real-time and convenience; 3) affordability; 4) noninvasiveness [8].

In the treatment of parathyroid adenoma, conservative medical treatment is not ideal. So surgical treatment has become the main treatment method. However, $95 \%$ of resection cases affect the gland and increase mortality in elderly patients [9] [10]. Surgical treatment can also damage the recurrent laryngeal nerve and cause hoarseness, with an incidence of about 5.8\% [11]. At the same time, the surgery is traumatic, with long period of treatment and relatively painful for the patient; while lumpectomy, although the skin incision is small, is difficult to show both the lesion and the surrounding important tissue structures due to the small visible scope under the microscope. And it is difficult to detect small deep and hidden lesions, which increases the difficulty of surgery. Surgical guidelines have been developed by the International Symposium on Primary Hyperparathyroidism, but many patients do not meet these guidelines [12]. This has generated a great interest in finding a therapeutic alternative to surgery. Nowadays, local anesthesia and minimally invasive non-surgical therapies are increasingly used to treat primary hyperparathyroidism (PHPT) [13]. Microwave ablation may be safe and effective for the treatment of recurrent and persistent secondary hyperparathyroidism nodules [14].

Microwave ablation (MWA) is a minimally invasive interventional treatment method. In 1995, Goldberg and Gazelle et al. [15] [16] were the first to report the application of MWA to the ablation of lung tissue in animals. Since then, many experimental and clinical research reports on microwave treatment of lung cancer have appeared. A wealth of clinical experience is accumulated, which enables it to become a treatment with clear effects. At present, in addition to lung tumors, microwave ablation technology has also been successfully used to treat various other solid tumors, such as liver tumors, bone tumors, kidney tumors, adrenal tumors, etc. [17] [18]; in addition to inactivating tumors, it can also reduce tumor load to achieve pain relief and reduce hormone secretion; furthermore, there are studies that apply it to non-tumor diseases such as the treatment of thyroid nodules [19] [20].

Ultrasound-guided microwave ablation can show the vascular blood flow in the surgical area, which can avoid and reduce the damage to blood vessels dur- 
ing the surgical operation. Together with ultrasound guidance throughout the whole process and in real time, it is more accurate to achieve a precise strike on the tumor. In this study, comparing the effect of microwave ablation with surgery in the treatment of parathyroid adenoma, we also found that the postoperative PTH, blood calcium and blood phosphorus levels of patients in both groups decreased significantly compared with those before surgery $(\mathrm{P}<0.05)$. And the serum parathyroid hormone (PTH), serum calcium and phosphorus levels decreased more rapidly in the surgery group than in the ablation group after surgery of 1, 3 and 6 months respectively. However, the length of hospital stay, operative time, and intraoperative bleeding were lower in the microwave ablation group than in the surgical group $(\mathrm{P}<0.05)$, and the complication rates were lower in both groups, with no statistically significant differences $(P>0.05)$, which indicated that both microwave ablation and surgical treatment of parathyroid adenoma are safe and effective.

\section{Conclusion}

In conclusion, in the treatment of primary parathyroid adenoma, both microwave ablation and surgery can effectively reduce serum parathyroid hormone (PTH), serum calcium and phosphorus levels and relieve nodule-related symptoms. At the same time, patients with microwave ablation have less intraoperative bleeding and shorter hospital stay and operation time, which are worthy of clinical promotion.

\section{Funding}

Funded by Project-WJ2019F127.

\section{Conflicts of Interest}

The authors declare no conflicts of interest regarding the publication of this paper.

\section{References}

[1] DeLellis, R.A. (1993) Tumors of the Parathyroid Gland. Atlas of Tumor Pathology. Armed Forces Institute of Pathology, Washington DC, 25-51.

[2] Zhu, J.Q., Liu, J.L., Li, X., et al. (1998) Diagnosis and Treatment of Primary Hyperparathyroidism. Chinese Journal of General Surgery Basic and Clinical, 5, 277-279.

[3] Liu, C., Wu, B., Huang, P., et al. (2016) US-Guided Percutaneous Microwave Ablation for Primary Hyperparathyroidism with Parathyroid Nodules: Feasibility and Safety Study. Journal of Vascular \& Interventional Radiology, 27, 867-875. https://doi.org/10.1016/j.jvir.2016.02.013

[4] Fraser, W.D. (2009) Hyperparathyroidism. The Lancet, 374, 145-158. https://doi.org/10.1016/S0140-6736(09)60507-9

[5] Doppman, J.L. and Miller, D.L. (1991) Localization of Parathyroid Tumors in Patients with Asymptomatic Hyperparathyroidism and No Previous Surgery. Journal of Bone and Mineral Research, 6, S153-S158. https://doi.org/10.1002/jbmr.5650061431

[6] Ahuja, A.T., Wong, K.T., Ching, A.S., et al. (2004) Imaging for Primary Hyperpa- 
rathyroidism-What Beginners Should Know. Clinical Radiology, 59, 967-976. https://doi.org/10.1016/j.crad.2004.04.005

[7] Randel, S.B., Gooding, G.A., Clark, O.H., et al. (1987) Parathyroid Variants: US Evaluation. Radiology, 165, 191-194.

https://doi.org/10.1148/radiology.165.1.3306784

[8] Duh, Q.Y., Sancho, J.J. and Clark, O.H. (1987) Parathyroid Localization. Clinical Review. Acta Chirurgica Scandinavica, 153, 241-254.

[9] Richards, M.L., Thompson, G.B., Farley, D.R., et al. (2008) Reoperative Parathyroidectomy in 228 Patients during the Era of Minimal-Access Surgery and Intraoperative Parathyroid Hormone Monitoring. The American Journal of Surgery, 196, 937-942. https://doi.org/10.1016/j.amjsurg.2008.07.022

[10] Hamdy, N.A. (2009) Parathyroid Gland: Is Parathyroidectomy Safe and Beneficial in the Elderly? Nature Reviews Endocrinology, 5, 422-423. https://doi.org/10.1038/nrendo.2009.142

[11] Liu, J.Y., Wei, S. and Gui, X.B. (2003) Surgery for Benign Thyroid Lesions and Injury to the Recurrent Laryngeal Nerve. Otolaryngology, Head and Neck Surgery, 10, 333-334.

[12] Farford, B., Presutti, R.J. and Moraghan, T.J. (2007) Nonsurgical Management of Primary Hyperparathyroidism. Mayo Clinic Proceedings, 82, 351-355. https://doi.org/10.1016/S0025-6196(11)61031-8

[13] Andrioli, M., Riganti, F., Pacella, C.M. and Valcavi, R. (2012) Long-Term Effectiveness of Ultrasound-Guided Laser Ablation of Hyperfunctioning Parathyroid Adenomas: Present and Future Perspectives. American Journal of Roentgenology, 199, 1164-1168. https://doi.org/10.2214/AJR.11.8442

[14] Yu, M.A., Yao, L., Zhang, L., et al. (2015) Safety and Efficiency of Microwave Ablation for Recurrent and Persistent Secondary Hyperparathyroidism after Parathyroidectomy: A Retrospective Pilot Study. International Journal of Hyperthermia, 32, 180-186.

[15] Goldberg, S.N., Gazelle, G.S. and Compton, C.C. (1995) Radiofrequency Tissue Ablation in the Rabbit Lung: Efficacy and Complications. Academic Radiology, 2, 776-784. https://doi.org/10.1016/S1076-6332(05)80852-9

[16] Goldberg, S.N., Gazelle, G.S., Compton, C.C., et al. (1996) Radio-Frequency Tissue Ablation of VX2 Tumor Nodules in the Rabbit Lung. Academic Radiology, 3, 929-935. https://doi.org/10.1016/S1076-6332(96)80303-5

[17] Ierardi, A.M., Puliti, A., Angileri, S.A., et al. (2017) Microwave Ablation of Malignant Renal Tumours: Intermediate-Term Results and Usefulness of RENAL and mRENAL Scores for Predicting Outcomes and Complications. Medical Oncology, 34, 97. https://doi.org/10.1007/s12032-017-0948-8

[18] Ward, R.C., Healey, T.T., Dupuy, D.E., et al. (2013) Microwave Ablation Devices for Interventional Oncology. Expert Review of Medical Devices, 10, 225-238. https://doi.org/10.1586/erd.12.77

[19] Yue, W., Wang, S., Wang, B., et al. (2013) Ultrasound Guided Percutaneous Microwave Ablation of Benign Thyroid Nodules: Safety and Imaging Follow-Up in 222 Patients. European Journal of Radiology, 82, 11-16. https://doi.org/10.1016/j.ejrad.2012.07.020

[20] Yue, W., Chen, L., Wang, S. and Yu, S. (2015) Locoregional Control of Recurrent Papillary Thyroid Carcinoma by Ultrasound-Guided Percutaneous Microwave Ablation: A Prospective Study. International Journal of Hyperthermia, 31, 403-408. https://doi.org/10.3109/02656736.2015.1014433 